\title{
Patogenicidade de isolados de Metarhizium anisopliae (Metsch.) Sorokin e de Beauveria bassiana (Bals.) Vuillemin a Scaptocoris carvalhoi Becker (Hemiptera, Cydnidae) ${ }^{1}$
}

\author{
Luciane Modenez Saldivar Xavier² \& Crébio José Ávila ${ }^{3}$
}

${ }^{1}$ Parte da Dissertação apresentada à Universidade Federal de Mato Grosso do Sul - UFMS - Programa de Mestrado em Entomologia e Conservação da Biodiversidade, para obtenção do título de Mestre em Entomologia.

${ }^{2}$ Universidade Federal da Grande Dourados - UFGD - BR 463, km 12, Caixa Postal 533, 79.804-970 Dourados-MS, Brasil.

luciane_modenez@ibest.com.br; luciane@insecta.ufv.br

${ }^{3}$ Embrapa Agropecuária Oeste. BR 163, km 253,6, Caixa Postal 661, 79.804-970 Dourados-MS, Brasil. crebio@cpao.embrapa.br.

\begin{abstract}
Pathogenicity of Metarhizium anisopliae (Metsch.) Sorokin and Beauveria bassiana (Bals.) Vuillemin isolates to Scaptocoris carvalhoi Becker (Hemiptera, Cydnidae). Pathogenicity of the fungi Metarhizium anisopliae (Metsch.) Sorokin and Beauveria bassiana (Bals.) Vuillemin to stinkbug Scaptocoris carvalhoi Becker, 1967 was evaluated under laboratory and greenhouse conditions. Experiments were carried out at Embrapa Agropecuária Oeste, Dourados, Mato Grosso do Sul State, Brazil, in 2003. Ten M. anisopliae and eleven B. bassiana isolates were evaluated in laboratory using a completely randomized experimental design with five replicates (10 adults and 5 nymphs/plot). The pathogenicity of $M$. anisopliae isolate (Ma69) was also separately evaluated against nymphs and adults in laboratory and greenhouse. The stinkbug mortality levels were higher for $M$. anisopliae isolates (between $73.3 \%$ and $94.7 \%$ than for B. bassiana isolates (between $10.7 \%$ and $78.7 \%$ ). In greenhouse, stinkbug mortality due to the M. anisopliae isolate (Ma69) was $57.3 \%$, and there was no difference of mortality for nymphs and adults of stinkbug in laboratory. However, in greenhouse, mortality levels were significantly higher $(p<0,05)$ for nymphs $(38,4 \%)$ than for adults $(16,2 \%)$. From these data, we conclude that $M$. anisopliae isolate Ma69 was efficient to control $S$. carvalhoi in laboratory and in greenhouse, thus being a promising choice for use as a microbial insecticide under field conditions.
\end{abstract}

KEYWORDS. Entomopathogenic fungus; microbial control; mortality.

RESUMO. Patogenicidade de isolados de Metarhizium anisopliae (Metsch.) Sorokin e de Beauveria bassiana (Bals.) Vuillemin a Scaptocoris carvalhoi Becker, 1967 (Hemiptera, Cydnidae). Avaliou-se a patogenicidade de isolados dos fungos Metarhizium anisopliae (Metsch.) Sorokin e Beauveria bassiana (Bals.) Vuillemin a Scaptocoris carvalhoi Becker, 1967 sob condições de laboratório e em casa de vegetação. Os experimentos foram conduzidos na Embrapa Agropecuária Oeste de Dourados, MS, durante o ano de 2003. Foram avaliados dez isolados de M. anisopliae e onze de B. bassiana, em laboratório, utilizando-se o delineamento inteiramente casualizado, com cinco repetições (10 adultos e 5 ninfas/parcela). A patogenicidade de M. anisopliae (Ma69) também foi testada em ninfas e adultos, separadamente, em laboratório e casa de vegetação. Os níveis de mortalidade do percevejo foram maiores com os isolados de M. anisopliae que variaram de $73,3 \%$ a $94,7 \%$ contra $10,7 \%$ a $78,7 \%$ para os de B. bassiana. Em casa de vegetação, a porcentagem de mortalidade do percevejo causada pelo fungo Ma69 foi de 57,3\% e não foi constatada diferença por este isolado quanto à mortalidade de ninfas e adultos, em laboratório. Todavia, em casa de vegetação, os níveis de mortalidade foram significativamente maiores $(p<0,05)$ para ninfas $(38,4 \%)$ do que para os adultos $(16,2 \%)$. Com base nos resultados obtidos, concluiu-se que o isolado Ma69 de M. anisopliae foi mais eficiente para S. carvalhoi tanto em laboratório quanto em casa de vegetação, constituindo em uma alternativa promissora para ser utilizado como inseticida microbiano em condições de campo.

PALAVRAS-CHAVE. Controle microbiano; fungo entomopatogênico; mortalidade.

O percevejo-castanho-da-raiz, Scaptocoris carvalhoi Becker, 1967 (sinonímia de Atarsocoris brachiariae Becker, 1996), a partir da década de 40 foi registrado em várias regiões do Brasil (Andrade \& Puzzi 1953). Na década de 80 a ocorrência desse inseto passou a ser mais intensa, causando danos principalmente em pastagens, soja e algodão, confirmando o que foi demonstrado por Grazia et al. (2004), ao descreverem que espécies do gênero Scaptocoris são prejudiciais a várias plantas cultivadas. Atualmente, o registro de danos econômicos dessa praga tem sido mais freqüente em regiões de Cerrado (Oliveira \& Malaguido 2004).

O percevejo castanho é considerado um inseto polífago e pode ocorrer em reboleiras, tanto em sistemas de semeadura direta como de convencional (Silva 1999) nas quais ninfas e adultos atacam as raízes das plantas (Tecnologias 2003). Em lavouras de soja, o diâmetro de cada foco de infestação pode variar de alguns metros a vários hectares (Oliveira et al. 2000). É um inseto de hábito subterrâneo e nas áreas infestadas, os sintomas nas plantas incluem murchamento e amarelecimento das folhas das plantas, com posterior seca e morte. Dentro das reboleiras, pode ser observada redução da população ou do crescimento das plantas atacadas, dependendo de quando o ataque ocorre. Causam danos pela retirada de seiva das raízes e pela injeção de saliva tóxica, o que provoca o enfraquecimento e morte das plantas (Fernandes et al. 1999; Raga et al. 2000; Fernandes et al. 2004). Nas épocas de seca, 
o percevejo castanho aprofunda-se no perfil do solo, retornando à superfície nos períodos chuvosos (Ceccon et al. 2004; Valério 2005).

Várias técnicas de redução populacional do percevejo castanho têm sido investigadas nos últimos anos, sendo o controle químico a predominante. Segundo Nakano (2004) e Fernandes et al. (2004), essa prática de controle é eficaz logo após as chuvas, pois no período de seca a distribuição da população da praga reduz a eficiência dos inseticidas. Nakano (2001) sugere o uso de sementes tratadas ou tratamento no sulco do plantio, semelhante ao que constataram Siloto et al. (2000) e Ceccon et al. (2004).

O controle cultural e físico do percevejo castanho também tem sido analisado. Oliveira \& Sales Jr. (2002) constataram que a adição de matéria orgânica contribuiu para a redução da população de A. brachiariae. Da mesma forma, Oliveira et al. (2003) avaliaram a associação entre a planta invasora mariamole (Senecio brasiliensis (Spreng.) Less) e Atarsocoris sp. e observaram uma correlação entre essas espécies, sugerindo a inclusão da maria-mole como bioindicadora desse percevejo nas áreas testadas.

O controle biológico tem se caracterizado como uma estratégia eficiente de redução populacional de muitos insetospraga (Van Driesche \& Bellows 1996), especialmente através do uso de agentes microbianos (Hajek \& St. Leger 1994). No Brasil, programas de controle com patógenos tiveram grandes avanços na última década, principalmente com o emprego de fungos (Madelin 1966; Carruthers \& Soper 1987; Faria \& Magalhães 2001). Dentre estes programas destaca-se o controle da cigarrinha da cana-de-açúcar Mahanarva posticata (Stal, 1855), prática realizada com sucesso nas últimas décadas (Alves 1998).

Os fungos Beauveria bassiana (Bals.) Vuillemin e Metarhizium anisopliae (Metsch.) Sorokin têm sido avaliados visando o controle de hemípteros considerados pragas (Borges et al. 1993; Sosa-Gómez et al. 1997; Alves 1998; Oliveira et al. 2001).

Especialmente em relação ao percevejo castanho, alguns isolados dos fungos $M$. anisopliae e $B$. bassiana também têm sido testados como prováveis agentes de controle. Assim, Malaguido et al. (2000) descreveram a ocorrência de fungos entomopatogênicos dos gêneros Metarhizium, Beauveria e Paecilomyces atacando o percevejo castanho, sendo esses considerados inimigos naturais e sua patogenicidade foi testada. O potencial de controle de M. anisopliae, isolado do próprio percevejo castanho foi testado em A. brachiariae por Amaral et al. (2002). Xavier \& Ávila (2005), também verificaram a patogenicidade de isolados deste fungo em S. carvalhoi.

Diante das evidências de patogenicidade de $M$. anisopliae e $B$. bassiana contra o percevejo castanho, a seleção de isolados desses fungos visando o controle do inseto poderá fornecer subsídios para o manejo dessa praga em condições de campo. A presente pesquisa teve por objetivo avaliar a patogenicidade de isolados dos fungos $M$. anisopliae e $B$. bassiana em $S$. carvalhoi, em condições de laboratório e em casa de vegetação.

\section{MATERIALE MÉTODOS}

Os experimentos foram conduzidos no Laboratório de Entomologia da Embrapa Agropecuária Oeste, em Dourados, MS, durante $o$ ano de 2003.

Obtenção dos insetos. Ninfas e adultos de S. carvalhoi foram coletados em lavouras de soja do município de São Gabriel do Oeste, MS (19 $23^{\circ} 42^{\prime \prime} \mathrm{S}$ e $\left.54^{\circ} 33^{\prime} 57^{\prime \prime} \mathrm{W}\right)$ e transportados em solo úmido, mantido em caixas de isopor. No laboratório, os insetos foram mantidos em temperatura ambiente, acondicionados (durante dois dias) em caixas de isopor sem tampa, contendo solo e raízes de algodoeiro, como alimento.

Obtenção e multiplicação dos isolados. Os vinte e um isolados testados pertencem à coleção de fungos entomopatogênicos da Embrapa Soja (Sosa-Gómez \& Silva 2002), os quais foram obtidos a partir de diversos hospedeiros e localidades (Tabela I). Os isolados foram enviados para o Laboratório de Entomologia, inoculados, individualmente, em tubos de vidro contendo meio de cultura Batata-DextroseÁgar (BDA) + antibiótico sulfato de estreptomicina e posteriormente armazenados em freezer $\left(-12^{\circ} \mathrm{C}\right)$. Para produção

Tabela I. Isolados de Metarhizium anisopliae e de Beauveria bassiana utilizados nos bioensaios com Scaptocoris carvalhoi ${ }^{1}$.

\begin{tabular}{|c|c|c|}
\hline Isolado & Hospedeiro & Coleções de Culturas \\
\hline \multirow{2}{*}{\multicolumn{3}{|c|}{$\begin{array}{l}\text { Metarhizium } \\
\text { anisopliae }(\mathrm{Ma})\end{array}$}} \\
\hline & & \\
\hline Ma 6 & Solo & Embrapa-Soja, PR \\
\hline Ma 7 & Solo & Embrapa-Soja, PR \\
\hline Ma 12 & Solo & Embrapa-Soja, PR \\
\hline Мa 69 & Phyllophaga cuyabana & Embrapa-Soja, PR \\
\hline Мa 98 & Sternechus subsignatus & Embrapa-Soja, PR \\
\hline Ma 136 & folíolo de soja & Embrapa-Soja, PR \\
\hline Ma 283 & Scaptocoris castanea & Embrapa-Soja, PR \\
\hline Ma 352 & Deois sp. & CP 225 CG491 \\
\hline Ma 356 & Piezodorus guildinii & CP 30 CG 144 \\
\hline Ma 358 & Ornithacris cavroisi & $\begin{array}{l}\text { IMI 330189ARSEF } \\
\text { 3341CG366 }\end{array}$ \\
\hline \multicolumn{3}{|c|}{$\begin{array}{l}\text { Beauveria } \\
\text { bassiana }(\mathrm{Bb})\end{array}$} \\
\hline $\mathrm{Bb} 8$ & Nezara viridula & Embrapa-Soja, PR \\
\hline $\mathrm{Bb} 14$ & Pentatomidae & ESALQ - 353 \\
\hline $\mathrm{Bb} 15$ & Euschistus heros & ESALQ - 457 \\
\hline $\mathrm{Bb} 16$ & Piezodorus guildinii & ESALQ - 458 \\
\hline $\mathrm{Bb} 20$ & Nezara viridula & ESALQ - 500CG78 \\
\hline $\mathrm{Bb} 37$ & Nezara viridula & $\begin{array}{l}\text { ESALQ - 620ARSEF } \\
1474\end{array}$ \\
\hline $\mathrm{Bb} 56$ & Nezara viridula & $\begin{array}{l}\text { ARSEF } 3954 \text { or } \\
\text { ARSEF } 39367\end{array}$ \\
\hline Bb 159 & Nezara viridula & Embrapa-Soja, PR \\
\hline $\mathrm{Bb} 161$ & Anticarsia gemmatalis & Embrapa-Soja, PR \\
\hline Bb 354 & Oryzophagus oryzae & Embrapa-Soja, PR \\
\hline Bb 357 & Diabrotica sp. & CG61 \\
\hline
\end{tabular}

${ }^{1}$ Catálogo de fungos entomopatogênicos (Sosa-Gómez e Silva 2002). 
de maior biomassa, os isolados foram repicados, separadamente, em placas de Petri contendo BDA e antibiótico tetraciclina, acondicionadas, durante dez dias, em estufa incubadora (B.O.D.) a $26 \pm 1^{\circ} \mathrm{C}$ e fotofase de $12 \mathrm{~h}$.

Para posteriores repicagens, estes isolados (biomassa total) foram acondicionados, separadamente, em tubos de vidro contendo sílica gel + leite desnatado (agente protetor) e armazenados em freezer $\left(-12^{\circ} \mathrm{C}\right)$ (Smith \& Onion 1983).

No preparo das suspensões, cada isolado foi multiplicado em placa de Petri (utilizando-se sílica gel impregnada com esporos) contendo meio de cultura BDA + antibiótico tetraciclina e mantidas em estufa incubadora nas mesmas condições descritas previamente. As suspensões fúngicas para os testes de patogenicidade foram preparadas adicionando-se $4 \mathrm{~mL}$ de solução contendo espalhante adesivo (Tween 80 a $0,01 \%$ ) nas placas dos isolados. Os conídios foram raspados do meio de cultura com auxílio de espátula, sendo o material fúngico filtrado utilizando-se tecido não tramado de viscose. Para homogeneizar, as suspensões foram agitadas em aparelho rotativo tipo vortex (Q-MED). Após isso, foram realizadas contagens de conídios em câmara de Neubauer para ajuste da concentração de $10^{8}$ conídios $/ \mathrm{mL}$ de suspensão.

A viabilidade dos conídios foi avaliada para cada isolado, utilizando-se quatro lâminas, contendo o meio BDA + antibiótico tetraciclina, mantidas em gerbox esterilizado, sendo a suspensão pulverizada, com aparelho nebulizador. Duas dessas lâminas foram analisadas, com auxílio do microscópio óptico com aumento de 40x, para verificar a quantidade de conídios. Havendo número suficiente de conídios, totalizando 100 conídios em cada avaliação, essas lâminas foram mantidas em B.O.D. a $26 \pm 1^{\circ} \mathrm{C}$, fotofase $12 \mathrm{~h}$ (por, no máximo, 24 horas) e, posteriormente, realizadas as contagens de conídios viáveis.

Avaliação dos isolados em laboratório. Os testes foram realizados em duas etapas. No ensaio 1 foram avaliados os isolados de M. anisopliae e no ensaio 2 os de B. bassiana. Os conídios foram aplicados topicamente sobre os insetos, com auxílio de um micropipetador automático, inoculando-se $5 \mu l$ da suspensão na região ventral e entre as coxas do percevejo. Após a inoculação, os insetos foram colocados em caixas plásticas do tipo gerbox $(11 \times 11 \times 3,5 \mathrm{~cm})$ com tampa, contendo 180 gramas de solo esterilizado e umedecido com $30 \mathrm{~mL}$ de água destilada e autoclavada. Raízes de algodoeiro tratadas com hipoclorito de sódio a $0,1 \%$ foram oferecidas aos insetos, como alimento. Essas caixas foram mantidas em câmaras climatizadas, reguladas para $26 \pm 1^{\circ} \mathrm{C}$, UR $85 \%$, sem fotofase.

$\mathrm{O}$ delineamento estatístico empregado foi o inteiramente casualizado, com 11 tratamentos no ensaio 1 (10 isolados de M. anisopliae e uma testemunha) e 12 no segundo ensaio (11 isolados de B. bassiana e uma testemunha), ambos com cinco repetições para cada tratamento, sendo cada uma constituída por 15 insetos (10 adultos +5 ninfas).

Avaliou-se a mortalidade dos insetos aos 5, 8, 12, e 15 dias após a inoculação dos fungos, efetuando-se a troca do alimento e repondo-se a umidade do solo no gerbox através da pesagem, quando necessário. Para a confirmação da causa mortis, os insetos foram colocados em placas de Petri esterilizadas contendo papel filtro esterilizado e um recipiente com algodão umedecido em água destilada e autoclavada. As placas foram vedadas com parafilme e mantidas a $26 \pm 1^{\circ} \mathrm{C}$, em $24 \mathrm{~h}$ de escotofase.

Os dados obtidos foram transformados para arcsen $\sqrt{(\mathrm{x} / 100)}$ e submetidos à análise de variância (teste $\mathrm{F})$, sendo as médias dos tratamentos comparadas pelo teste de Tukey, ambos a $5 \%$ de probabilidade.

Avaliação de $M$. anisopliae a ninfas e adultos em laboratório. $\mathrm{O}$ isolado Ma69 foi selecionado para os testes com ninfas e adultos pois foi o mais patogênico. Neste sentido, ninfas e adultos de $S$. carvalhoi foram submetidos à sua ação para comparar a suscetibilidade desses dois estádios de desenvolvimento ao patógeno, conforme metodologia descrita nos ensaios anteriores, inclusive para a avaliação da mortalidade e da causa mortis.

$\mathrm{O}$ experimento foi conduzido no arranjo fatorial 2:2 (presença/ausência do fungo: estádio de desenvolvimento do percevejo) no delineamento inteiramente casualizado com 5 repetições, cada uma constituída por 15 ninfas ou 15 adultos, tanto nos tratamentos com fungos quanto na testemunha (sem fungo).

Os dados de mortalidade ( $\mathrm{x}$ ) foram transformados para $\operatorname{arcsen} \sqrt{(\mathrm{x} / 100)}$ e submetidos à análise de variância (teste $\mathrm{F}$ ), sendo as médias dos tratamentos comparados pelo teste de Tukey a $5 \%$ de probabilidade.

Patogenicidade de $M$. anisopliae em casa de vegetação. $\mathrm{O}$ isolado Ma69 foi multiplicado na Embrapa Soja, sendo os conídios produzidos em arroz cozido, como meio de cultura, conforme metodologia de Leite et al. (2003).

Para instalação dos bioensaios, padronizou-se a concentração do inóculo. As parcelas foram constituídas por vasos de $5 \mathrm{~L}$, contendo $4 \mathrm{~kg}$ de terra peneirada, retirada do mesmo local em que os insetos foram coletados, umedecida com $400 \mathrm{~mL}$ de água destilada e acrescentadas quatro raízes e oito sementes de algodoeiro em cada vaso, fornecidos como alimento. Em seguida, em cerca de $5 \mathrm{~cm}$ de profundidade da terra do vaso, foram adicionados $0,17 \mathrm{~g}$ de conídios do fungo $\mathrm{e}$, sobre esses, os insetos (quantidade equivalente a $10^{13}$ conídios/ha).

No primeiro ensaio, a ação do isolado Ma69 a S. carvalhoi foi avaliada seguindo o delineamento inteiramente casualizado, contendo dois tratamentos (com fungo e sem fungo) e 12 repetições, sendo cada uma constituída por 15 insetos (10 adultos +5 ninfas). Em outro bioensaio, adultos e ninfas do inseto foram avaliados separadamente. Neste caso, o experimento foi conduzido no arranjo fatorial 2:2 (presença/ ausência do fungo: estádio de desenvolvimento do percevejo) no delineamento inteiramente casualizado com 5 repetições, para cada fase (adulto ou ninfa) tratada com fungo e uma testemunha (sem tratamento), totalizando 4 tratamentos.

A mortalidade, em ambos bioensaios, foi avaliada aos 12 
dias após a instalação do experimento, sendo a umidade dos vasos reposta, quando necessário (pesando-se, individualmente, os vasos para manter a umidade inicial) e acondicionados em umidade do ar e temperatura ambientes, sendo, esta última, registrada durante o período experimental. Para a determinação da causa mortis foi utilizada a mesma metodologia empregada nos bioensaios de laboratório.

Os valores de mortalidade, no primeiro ensaio, foram comparados pelo teste de t a $5 \%$ de probabilidade e no segundo ensaio os dados de mortalidade (x) foram transformados e comparados como descrito anteriormente.

\section{RESULTADOS EDISCUSSÃO}

Avaliação dos isolados em laboratório. Todos os isolados avaliados apresentaram viabilidade média acima de 95\%, o que confere valor ideal para bioensaios com fungos (Alves et al. 1998).

No ensaio 1, o isolado Ma352 apresentou maior índice de mortalidade sobre S. carvalhoi $(94,7 \%)$, embora fosse significativamente superior apenas ao isolado Ma12, enquanto os demais isolados não diferiram entre si (Tabela II).

No ensaio com $B$. bassiana, a mortalidade do percevejo foi superior com o isolado Bb14, sendo significativamente superior aos demais isolados de B. bassiana, exceto para Bb161 e Bb16, os quais não diferiram entre si (Tabela III). Além disso, nesse ensaio houve maior variação dos níveis de mortalidade entre os isolados testados, sendo que Bb14, Bb161 e Bb16 diferiram de Bb159 e Bb357, o mesmo ocorrendo entre os isolados Bb37 e Bb357.

Dentre os 21 isolados de fungos testados, somente sete de $M$. anisopliae causaram mortalidade a $S$. carvalhoi superior a $80 \%$, nível satisfatório de controle para que um inseticida possa ser considerado eficiente do ponto de vista agronômico. De um modo geral, os níveis de mortalidade do percevejo foram maiores para os isolados de $M$. anisopliae que variaram de $73,3 \%$ a $94,7 \%$ contra $10,7 \%$ a $78,7 \%$ de $B$. bassiana (Tabela II e III).

Tabela II. Mortalidade confirmada de ninfas e adultos de Scaptocoris carvalhoi por Metarhizium anisopliae $\left(10^{8}\right.$ conídios $\left./ \mathrm{mL}\right)$, após 15 dias de inoculação.

\begin{tabular}{cc}
\hline Tratamento & Mortalidade $(\%)$ \\
\hline Ma 352 & $94,7 \pm 3,27 \mathrm{a}$ \\
Ma 69 & $92,0 \pm 4,90 \mathrm{ab}$ \\
Ma 7 & $89,3 \pm 5,81 \mathrm{ab}$ \\
Ma 283 & $90,7 \pm 2,67 \mathrm{ab}$ \\
Ma 6 & $84,0 \pm 4,00 \mathrm{ab}$ \\
Ma 356 & $81,3 \pm 9,04 \mathrm{ab}$ \\
Ma 136 & $82,7 \pm 4,00 \mathrm{ab}$ \\
Ma 358 & $78,7 \pm 2,49 \mathrm{ab}$ \\
Ma 98 & $77,3 \pm 3,40 \mathrm{ab}$ \\
Ma 12 & $73,3 \pm 4,71$ b \\
Testemunha & $0,0 \pm 0,00 \quad \mathrm{c}$
\end{tabular}

Médias ( \pm EP) seguidas por letras distintas diferem entre si pelo teste de Tukey a $5 \%$ de probabilidade.
Tabela III. Mortalidade confirmada de ninfas e adultos de Scaptocoris carvalhoi por Beauveria bassiana $\left(10^{8}\right.$ conídios $\left./ \mathrm{mL}\right)$, após 15 dias de inoculação.

\begin{tabular}{cc}
\hline Tratamento & Mortalidade $(\%)$ \\
\hline Bb 14 & $78,7 \pm 4,42$ a \\
Bb 161 & $62,7 \pm 5,42 \quad$ ab \\
Bb 16 & $58,7 \pm 3,89$ ab \\
Bb 354 & $48,0 \pm 11,23 \quad$ b \\
Bb 8 & $41,3 \pm 5,73 \quad$ b \\
Bb 15 & $37,3 \pm 4,99 \quad$ b \\
Bb 37 & $35,3 \pm 2,84 \quad$ bc \\
Bb 20 & $33,3 \pm 4,71 \quad$ bcd \\
Bb 56 & $32,0 \pm 3,27 \quad$ bcd \\
Bb 159 & $13,3 \pm 5,58 \quad$ cd \\
Bb 357 & $10,7 \pm 3,40 \quad$ de \\
Testemunha & $0,0 \pm 0,00 \quad$ e
\end{tabular}

Médias ( \pm EP) seguidas por letras distintas diferem entre si pelo teste de Tukey a $5 \%$ de probabilidade.

A ação dos fungos M. anisopliae e de B. bassiana sobre o percevejo castanho também foi testado em laboratório por Malaguido et al. (2000), com aplicação tópica de $5 \mu 1 /$ percevejo (30.000 conídios/inseto), no qual obtiveram mortalidades de $31 \%$ e $38 \%$, respectivamente, para esses dois fungos. Quando os mesmos autores utilizaram os fungos em maior concentração, em mistura com caulim, através de polvilhamento, a eficiência de $M$. anisopliae foi aumentada, atingindo $63 \%$ de mortalidade, enquanto que para B. bassiana permaneceu com $37 \%$. Portanto, os índices de mortalidade obtidos por esses autores foram inferiores aos da presente pesquisa. Xavier \& Ávila (2005) avaliaram a patogenicidade de quatro isolados de M. anisopliae em S. carvalhoi, utilizando metodologia semelhante à utilizada neste bioensaio e constataram porcentagem de mortalidade variando de $56,7 \%$ a $96,7 \%$, à semelhança dos resultados nesta pesquisa.

Com base nos resultados com os isolados de B. bassiana houve baixa eficiência de controle de $S$. carvalhoi, porém com M. anisopliae seu potencial viabiliza o seu emprego em condições de campo.

Avaliação de M. anisopliae a ninfas e adultos em laboratório. Não foi constatada interação dos fatores fungo e estádio de desenvolvimento do percevejo. Todavia, verificouse uma acentuada mortalidade do inseto $(88,0 \%)$ na presença do fungo, com os dois estádios de desenvolvimento do percevejo (adultos e ninfas) apresentando níveis de mortalidade semelhantes tanto na presença como na ausência do fungo (Tabela IV).

Patogenicidade de M. anisopliae em casa de vegetação. A temperatura média diária registrada em casa de vegetação, durante o período experimental, foi de $28,7 \pm 1,9$ com variações de mínima e máxima de $21,1 \pm 1,7$ e 36,4 $\pm 3,4$, respectivamente. Nos vasos contendo o fungo Ma69, a percentagem de mortalidade de adultos e ninfas de S. carvalhoi foi de 57,3\%, enquanto nos vasos sem fungo a mortalidade do percevejo foi de $7,5 \%$ (Tabela V). 
Tabela IV. Mortalidade confirmada de ninfas e adultos de Scaptocoris carvalhoi na presença e ausência do fungo Metarhizium anisopliae (Ma69) em laboratório, após 15 dias de inoculação.

\begin{tabular}{ll}
\hline Tratamento & Mortalidade $^{1}(\%)$ \\
\hline Fungos & $88,0 \mathrm{a}$ \\
Testemunha & $2,0 \quad \mathrm{~b}$ \\
\hline Tratamento & Mortalidade $^{2}(\%)$ \\
\hline Adultos & $45,34 \mathrm{a}$ \\
Ninfas & $44,67 \mathrm{a}$ \\
\hline
\end{tabular}

${ }^{1} \mathrm{Ninfas}+$ adultos

${ }^{2}$ Com e sem fungo

Médias seguidas por letras distintas diferem entre si pelo teste Tukey a $5 \%$ de probabilidade.

Quando ninfas e adultos foram submetidos à presença do fungo separadamente, foi constatado interação dos fatores fungo e estádio de desenvolvimento do percevejo, sendo observado uma maior mortalidade do inseto na presença do fungo em relação a ausência deste, bem como significativamente maior mortalidade das ninfas do que de adultos (Tabela VI). Esses resultados diferem daqueles obtidos em laboratório, em que não foi constatada diferença significativa para os níveis de mortalidade nos dois estádios de desenvolvimento do inseto tanto na presença como na ausência do fungo. As mortalidades obtidas nos tratamentos testemunha (Tabelas IV, V e VI) ocorreram, provavelmente devido à manipulação por ocasião da instalação do experimento, durante a avaliação de mortalidade ou contaminação do fungo no solo, onde os percevejos foram coletados.

A diferença na patogenicidade entre ninfas e adultos no laboratório e em casa de vegetação pode estar relacionada ao modo de inoculação do patógeno, sendo que no laboratório o fungo foi aplicado diretamente sobre o corpo do inseto, enquanto que em casa de vegetação foi colocado no solo. A fixação dos conídios no inseto hospedeiro representa o evento inicial no estabelecimento de micoses (Boucias et al. 1988), sendo que os fungos infectam o hospedeiro via cutícula, aderem e germinam, formando uma série de infecções estruturais durante a penetração (St. Leger et al. 1991).

No entanto, a diferença de suscetibilidade nos diferentes estádios do inseto em casa de vegetação, pode estar relacionada às diferentes características do tegumento durante estas fases. De acordo com Sosa-Gómez et al. (1997), várias atividades fúngicas têm sido associadas com a cutícula do inseto durante diferentes fases. Tanada (1956) também descreveu que, diferenças de suscetibilidade que ocorrem devido aos diferentes estádios de desenvolvimento dos insetos, são proporcionadas por um aumento indireto em resistência ao entomopatógeno com a idade, fato que tem sido registrado em resposta a vários hospedeiros de insetos a diferentes patógenos. O tegumento dos insetos, sendo essencialmente composto por proteínas e quitina associadas com lipídios e compostos fenólicos (Ferron 1978), possui alguns aldeídos presentes no tegumento que podem inibir a
Tabela V. Mortalidade confirmada de ninfas e adultos de Scaptocoris carvalhoi sobre o efeito de Metarhizium anisopliae. (Ma69) em casa de vegetação, 12 dias após o início do experimento.

\begin{tabular}{lc}
\hline Tratamento & Mortalidade $(\%)$ \\
\hline Percevejos tratados & $57,3 \pm 4,93 \mathrm{a}$ \\
Percevejos não tratados & $7,5 \pm 1,99 \quad$ b \\
\hline
\end{tabular}

Médias $( \pm \mathrm{EP})$ seguidas por letras distintas diferem entre si pelo teste de $\mathrm{t}$ a $5 \%$ de probabilidade.

germinação dos conídios de M. anisopliae e atrasar o desenvolvimento do tubo germinativo dos fungos entomopatogênicos (Borges et al. 1993; Sosa-Gómez et al. 1997), uma vez que o nível de aldeídos na cutícula está relacionado com a idade do inseto. Segundo Pavis et al. (1994) ninfas de primeiro ínstar de Nezara viridula (Linnaeus, 1758) produzem baixo índice do aldeído (feromônio de alarme). A menor quantidade de aldeído na cutícula dessas ninfas observada por esses autores pode justificar a maior suscetibilidade a fungos entomopatogênicos nessa fase aqui constatada, explicando o porquê das ninfas serem suscetíveis à ação de fungos quando comparadas aos adultos.

Pesquisas que demonstram qual a fase do inseto é mais vulnerável à ação de fungos podem auxiliar na determinação do momento em que o fungo deve ser aplicado a campo, de modo a maximizar a eficácia de controle. Segundo Alves (1998), a aplicação a campo de $M$. anisopliae tende a proporcionar maior índice de controle sobre ninfas das cigarrinhas-daspastagens dos gêneros Mahanarva, Deois e Zulia. O mesmo ocorre com as cigarrinhas da cana-de-açúcar M. posticata (Stal, 1855) e Mahanarva fimbriolata (Stal, 1854), que segundo esse autor, foram mais suscetíveis ao fungo na fase ninfal.

Nesta pesquisa, os resultados obtidos em casa de vegetação indicam que em campo, a aplicação desse fungo deve coincidir com maior população de ninfas. Assim, estudos sobre a flutuação populacional são fundamentais para auxiliar no manejo integrado desse inseto, sendo que Oliveira \& Malaguido (2004) ao observarem a flutuação populacional de Scaptocoris castanea Perty, 1833 em Sapezal, MT durante dezembro/98 a maio/2000, descreveram que as ninfas foram mais abundantes de junho a outubro.

Tabela VI. Mortalidade confirmada de ninfas e adultos de Scaptocoris carvalhoi na presença e ausência do fungo Metarhizium anisopliae (Ma69) em casa de vegetação, 12 dias após o início do experimento.

\begin{tabular}{ll}
\hline Tratamento & Mortalidade $^{1}(\%)$ \\
\hline Fungo & $53,3 \mathrm{a}$ \\
Testemunha & $3,25 \mathrm{~b}$ \\
\hline Tratamento & Mortalidade $^{2}(\%)$ \\
\hline Adultos & $16,2 \mathrm{~b}$ \\
Ninfas & $38,4 \mathrm{a}$ \\
\hline
\end{tabular}

${ }^{1}$ Ninfas + adultos

${ }^{2}$ Com e sem fungo

Médias seguidas por letras distintas diferem entre si pelo teste Tukey a $5 \%$ de probabilidade. 
Os resultados obtidos nesta pesquisa em casa de vegetação, fornecem suporte para o controle microbiano de $S$. carvalhoi com M. anisopliae, uma vez que, alternativas de controle utilizadas em associação, poderão alcançar índices satisfatórios de redução populacional desta praga (Valério 2005). Portanto conclui-se que o isolado Ma69 apresenta potencial para utilização no controle de $S$. carvalhoi, sendo necessária a realização de estudos em condições de campo e também para determinar as condições ambientais que favoreçam sua ação.

Agradecimentos. À CAPES, pela concessão de bolsa ao primeiro autor. Ao FUNDECT, pelo financiamento do projeto. À EMBRAPASoja pelo envio dos isolados de fungos entomopatogênicos testados, especialmente ao Dr. Daniel R. Sosa Gómez. À Dra. Jocelia Grazia da UFRGS/Porto Alegre, RS pela identificação do inseto estudado.

\section{REFERÊNCIAS}

Alves, S. B.; J. E. M. Almeida; A. Moino Jr. \& L. F. A. Alves. 1998. Técnicas de laboratório, p. 637-711. In: S. B. Alves (ed.). Controle Microbiano de Insetos. Piracicaba, FEALQ, 1163 p.

Alves, S. B. 1998. Fungos entomopatogênicos, p. 289-381. In: S. B. Alves (ed.). Controle Microbiano de Insetos. Piracicaba, FEALQ, 1163 p.

Amaral, J. L.; D. C. Souza; R. L. C. Souza; L. R. B. Correa; S. L. Maidana; L. M. S. Fernandes \& R. A. Castro. 2002. Associação de subdosagens de inseticidas sistêmicos e não sistêmicos com o fungo Metarhizium anisopliae no controle do percevejo castanho das raízes em pastagens. Biodiversidade (UFMT) 1: 4-11.

Andrade, A. C. \& D. Puzzi. 1953. Experiências com inseticidas orgânicos para controlar o "percevejo castanho" (Scaptocoris castaneus) em cana-de-açúcar. O Biológico 19: 187-189.

Borges, M.; S. C. M. Leal; M. S. Tigano-Milani \& M. C. C. Valadares. 1993. Efeito do feromônio de alarme do percevejo verde, Nezara viridula (L.) (Hemiptera: Pentatomidae), sobre o fungo entomopatogênico Metarhizium anisopliae (Metsch.) Sorok. Anais da Sociedade Entomológica do Brasil 22: 505-512.

Boucias, D. G.; J. C. Pendland \& J. P. Latge. 1988. Nonspecific factors involved in attachment of entomopathogenic deuteromycetes to host insect cuticle. Applied and Environmental Microbiology 54: $1795-1805$.

Carruthers, R. I. \& R. S. Soper. 1987. Fungal diseases, p. 357-416. In: Fuxa, J. R. \& Y. Tanada (eds.). Epizootiology of Insect Diseases. United States, John Wiley \& Sons, 555p.

Ceccon, G.; A. Raga; A. P. Duarte \& R. C. Siloto. 2004. Efeito de inseticidas na semeadura sobre pragas inicias e produtividade de milho safrinha em plantio direto. Bragantia 63: 227-237.

Faria, M. R. \& B. P. Magalhães. 2001. O uso de fungos entomopatogênicos no Brasil. Biotecnologia Ciência \& Desenvolvimento 22: 18-21.

Fernandes, P. M.; I. R. O. Cruvinel; K. Kobus; C. Czepak \& V. R. S. Veloso. 1999. O percevejo castanho em áreas agrícolas do bioma cerrado. In: Reunião Sul Brasileira sobre Pragas de Solo, 7., 1999, Piracicaba, Anais e ata...Piracicaba, Fealq, p. 49-53.

Fernandes, P. M.; L. J. Oliveira; C. R. Souza; C. Czepak \& R. G. Barros. 2004. Percevejos-castanhos, p. 477-494. In: J. R. Salvadori; C. J. Ávila \& M. T. B. Silva (eds.). Pragas de Solo no Brasil. Passo Fundo: Embrapa Trigo; Dourados : Embrapa Agropecuária Oeste; Cruz Alta : Fundacep Fecotrigo. 544p.
Ferron, P. 1978. Biological control of insect pests by entomogenous fungi. Annual Review of Entomology 23: 409-442.

Grazia, J.; C. F. Schwertner \& E. J. E. Silva. 2004. Arranjos taxonômicos e nomenclaturais em Scaptocorini (Hemiptera: Cydnidae, Cephalocteinae). Neotropical Entomology 33: 511-512.

Hajek, A. E. \& R. J. St. Leger. 1994. Interactions between fungal pathogens and insect hosts. Annual Review of Entomology 39: 293-322.

Leite, L. G.; A. Batista Filho; J. E. M. Almeida \& S. B. Alves. 2003. Produção de Fungos Entomopatogênicos. Ribeirão Preto. 92p.

Madelin, M. F. 1966. Fungal parasites of insects. Annual Review of Entomology 11: 423-448.

Malaguido, A. B.; L. J. Oliveira \& D. R. Sosa-Gómez. 2000. Efeito de fungos entomopatogênicos sobre o percevejo-castanho-da-raiz. In: L. J. Oliveira (org.). Efeito de inseticidas químicos e de fungos entomopatogênicos sobre o percevejo-castanho-da-raiz: resultados da safra 1999/2000. Londrina, Embrapa-Soja, p.3236. (Documentos, 150).

Nakano, O. 2001. Oscilações do controle de pragas do algodoeiro no Brasil. In: Congresso Brasileiro de Algodão, 3., 2001, Campo Grande, Produzir sempre, o grande desafio: resumos das palestras. Campina Grande, Embrapa Algodão; Campo Grande, UFMS; Dourados, Embrapa Agropecuária Oeste, p. 30-34.

Nakano, O. 2004. Ainda ameaçador. Cultivar 58: 18-21.

Oliveira, L. J.; A. B. Malaguido; J. Nunes Jr; I. C. Corso; S. Angelis; L. C. Faria; C. B. Hoffmann-Campo \& A. F. Lantmann. 2000. Percevejo-castanho-da-raiz em sistemas de produção de soja. Londrina, Embrapa Soja, 44p. (Circular Técnica, 28).

Oliveira, M. A. S.; R. T. Alves; J. F. Fialho \& N. T. V. Junqueira. 2001. Patogenicidade de fungos entomógenos sobre o percevejode-renda da mandioca no Distrito Federal. Planaltina, Embrapa Cerrados, 2p. (Circular Técnica, 45).

Oliveira, C. \& O. Sales Junior. 2002. Utilização de diferentes técnicas para o manejo do percevejo castanho Atarsocoris brachiariae Becker, 1996. Biodiversidade (UFMT) 1: 110-115.

Oliveira, E. D. M.; A. Pasini \& I. C. B. Fonseca. 2003. Association of the soil bug Atarsocoris sp. (Hemiptera: Cydnidae) with the weed Senecio brasiliensis Less. Neotropical Entomology 32: 155157.

Oliveira, L. J. \& A. B. Malaguido. 2004. Flutuação e distribuição vertical da população do percevejo castanho da raiz, Scaptocoris castanea Perty (Hemiptera:Cydnidae), no perfil do solo em áreas produtoras de soja nas regiões centro-oeste e sudeste do Brasil. Neotropical Entomology 33: 283-291.

Pavis, C.; C. Malosse; P. H. Ducrot \& C. Descoins. 1994. Dorsal abdominal glands in nymphs of southern green stink bug, Nezara viridula (L.) (Heteroptera: Pentatomidae): chemistry of secretions of five instars and role of (e)-4-oxo-2-decenal, compound specific to first instars. Journal of Chemical Ecology 20: 2213-2227.

Raga, A.; R. C. Siloto \& M. E. Sato. 2000. Efeito de inseticidas sobre o percevejo castanho Scaptocoris castanea (Hem.: Cydnidae) na cultura algodoeira. Arquivos do Instituto Biológico 67: 93-97.

Silva, C. A. D. 1999. Percevejo castanho: ou ele ou o algodão. Cultivar 4: 16-17.

Siloto, R. C.; M. E. Sato \& A. Raga. 2000. Efeito de inseticidas sobre percevejo castanho em cultura de milho-safrinha. Revista de Agricultura 75: 21-27.

Smith, D \& A. H. S. Onion. 1983. The Preservation and Maintenance of Living Fungi. Kew: International Mycological Institute. 51 p. 1983.

Sosa-Gómez, D. R.; D. G. Boucias \& J. L. Nation. 1997. Attachment of Metarhizium anisopliae to the southern green stink bug Nezara viridula cuticle and fungistatic effect of cuticular lipids and 
aldehydes. Journal of Invertebrate Pathology 69: 31-39.

Sosa-Gómez, D. R. \& J. J. Silva. 2002. Fungos entomopatogênicos: catálogo de fungos. Londrina, Embrapa Soja, 32 p. (Documentos, 188).

St. Leger, R. J.; M. Goettel; D. W. Roberts \& R. C. Staples. 1991. Prepenetration events during infection of host cuticle by Metarhizium anisopliae. Journal of Invertebrate Pathology 58: $168-179$.

Tanada, Y. 1956. Some factors affecting the susceptibility of the armyworm to virus infections. Journal of Econnomic Entomology 49: 52-57.
Tecnologia de Produção de Soja: Região Central do Brasil 2004. Londrina: Embrapa Soja, 2003. p. 177-178. (Embrapa Soja. Sistema de Produção, 4).

Valério, J. R. 2005. Insetos-praga em pastagens tropicais. Informe Agropecuário 26: 98-110.

Van Driesche, R. G. \& T. S. Bellows Jr. 1996. Biological Control. New York: Chapmann \& Hall, 539p.

Xavier, L. M. S. \& C. J. Ávila. 2005. Patogenicidade, $\mathrm{DL}_{50}$ e $\mathrm{TL}_{50}$ de isolados de Metarhizium anisopliae (Metsch.) Sorok. para o percevejo castanho das raízes Scaptocoris carvalhoi Becker (Hemiptera: Cydnidae). Ciência Rural 35: 763-768. 